\title{
Does carbon pricing reduce air travel? Evidence from the Australian 'Clean Energy Future' policy, July 2012 to June 2014
}

\author{
Francis Markham ${ }^{1}$, Martin Young ${ }^{2}$, Arianne Reis ${ }^{3}$ \& James \\ Higham $^{4}$
}

Centre for Aboriginal Economic Policy Research, The Australian National University, Canberra, ACT, Australia ${ }^{1} \bullet$ School of Business and Tourism, Southern Cross University, Coffs Harbour, NSW, Australia ${ }^{2} \bullet$ School of Science and Health, Western Sydney University, Sydney, NSW, Australia ${ }^{3} \bullet$ Department of Tourism, University of Otago, Dunedin, New Zealand ${ }^{4}$

Correspondence to: Francis Markham. E-mail: francis.markham@anu.edu.au

This is an Accepted Manuscript of an article that will be published by Elsevier in a forthcoming issue of Journal of Transport Geography. The manuscript was accepted for publication 12 June 2018.

This work should be cited as:

Markham, F., Young, M., Reis, A. \& Higham, J. (2018). Does carbon pricing reduce air travel? Evidence from the Australian 'Clean Energy Future' policy, July 2012 to June 2014. Manuscript accepted for publication in Journal of Transport Geography.

\begin{abstract}
Aviation emissions are an important contributor to global climatic change. As growth in travel demand continues to outstrip improvements in the fuel efficiency of air travel, the aviation contribution to climate change is likely to grow substantially. Consequently, measures that effectively reduce travel demand are required if atmospheric carbon concentrations are to be limited. The efficacy of the Australian Clean Energy Future policy which placed a \$23.00AUD (FY 2012) to \$24.15 AUD (FY 2013) per tonne levy on carbon-dioxide equivalent emissions from July 2012 to June 2014 is tested. Specifically, time-series regression is used to estimate the effect of this carbon price policy on the level of domestic passenger kilometres flown in Australia, while adjusting for costs of production (i.e. fuel and labour costs), economic activity (i.e. gross domestic product), competitive effects (i.e. airline capacity), and exogenous shocks. There was no evidence that the carbon price reduced the level of domestic aviation in Australia. Carbon pricing measures may have to be levied at a greater rate to affect behavioural change, particularly given the limited potential for future aviation efficiency gains.
\end{abstract}

Keywords air travel; aviation; carbon pricing; climate change; emissions; Australia 


\section{Introduction}

\subsection{Growth in global and Australian air traffic}

The number of people transported by plane has increased more than tenfold since the 1970s, reaching a staggering 3.7 billion passengers in 2016 (World Bank, 2017). Global passenger traffic for 2016, measured by revenue passenger kilometers (RPKs), rose by approximately $7.4 \%$ (to 7,127 billion) on the previous year, and airline capacity, measured by available seat kilometers, was also up approximately 7.4\% (ICAO, 2017d). Increased demand has translated into near record profitability, with global airline net profits (after interest charges, taxes, and write-downs) for 2016 of $\$ 34.8$ billion, an aggregate operating margin of $8.9 \%$, and record load factor of $80.4 \%$ (IATA, 2017: 14). The industry forecasts growth in airline traffic of $4.7 \%$ p.a. for the next 20 years, with total jets in service in forecast to increase from 23,480 in 2016 to 46,950 by 2036 (Boeing, 2017: 79). This level of aero-mobility has well documented impacts on the global climate via emissions of carbon dioxide $\left(\mathrm{CO}_{2}\right)$, nitrogen oxides (NOx), aerosols and their precursors (soot and sulphate), persistent linear contrails and induced-cirrus cloudiness (Lee et al., 2009). Aviation accounts for an estimated 4.9\% of the anthropogenic component of global warming and this proportion is forecast to increase significantly over time (Lee et al., 2009). A meta-analysis of published travel demand projections found that the median estimated increase in global aviation emissions was an increase of $350 \%$ between the years 2000 and 2050 (Gudmundsson and Anger, 2012).

The rapid increase in aviation emissions results from a level of demand that far outstrips any improvements in the fuel efficiency of aircraft fleets. Aviation emissions are particularly resistant to reduction because the marginal efficiency gains of aircraft technology appear to have been largely exhausted. The jet aircraft has reached a stage of technological maturity that only allows for minor and incremental efficiency gains (Bows et al., 2009). Indeed, most of the technological 'solutions' that have been presented over the past 20 years, including solar passenger planes, redesigned planes, and biofuels, are either technically impossible, commercially infeasible, more polluting than fossil fuels, or incapable of materially reducing emissions (Peeters et al., 2016: 40). Unlike other forms of transport and industry, the energy source of aviation is not readily substitutable. Coal-fired power stations can be replaced by nuclear, wind, and solar power. Road- and rail-based passenger vehicles can transition from oil-based fuels to renewably-sourced electricity. For jet engines, the options for technology switching are very limited (Stern, 2006: 337). This means that in the absence of radical technological change - the substitution of the jet engine with a clean technology - aviation remains an intractable environmental problem (Lee et al., 2009). In Australia, this is evident in the amount of aviation fuel used per head of population over time (Figure 1). While there have been sharp intermittent falls in per capital fuel consumption due to external shocks (including significant industrial action by pilots in 1989 and the collapse of the domestic airline Ansett in 2001), the general trend is an ongoing increase in air travel demand at a rate that has outstripped improvements in efficiency by a considerable margin. 


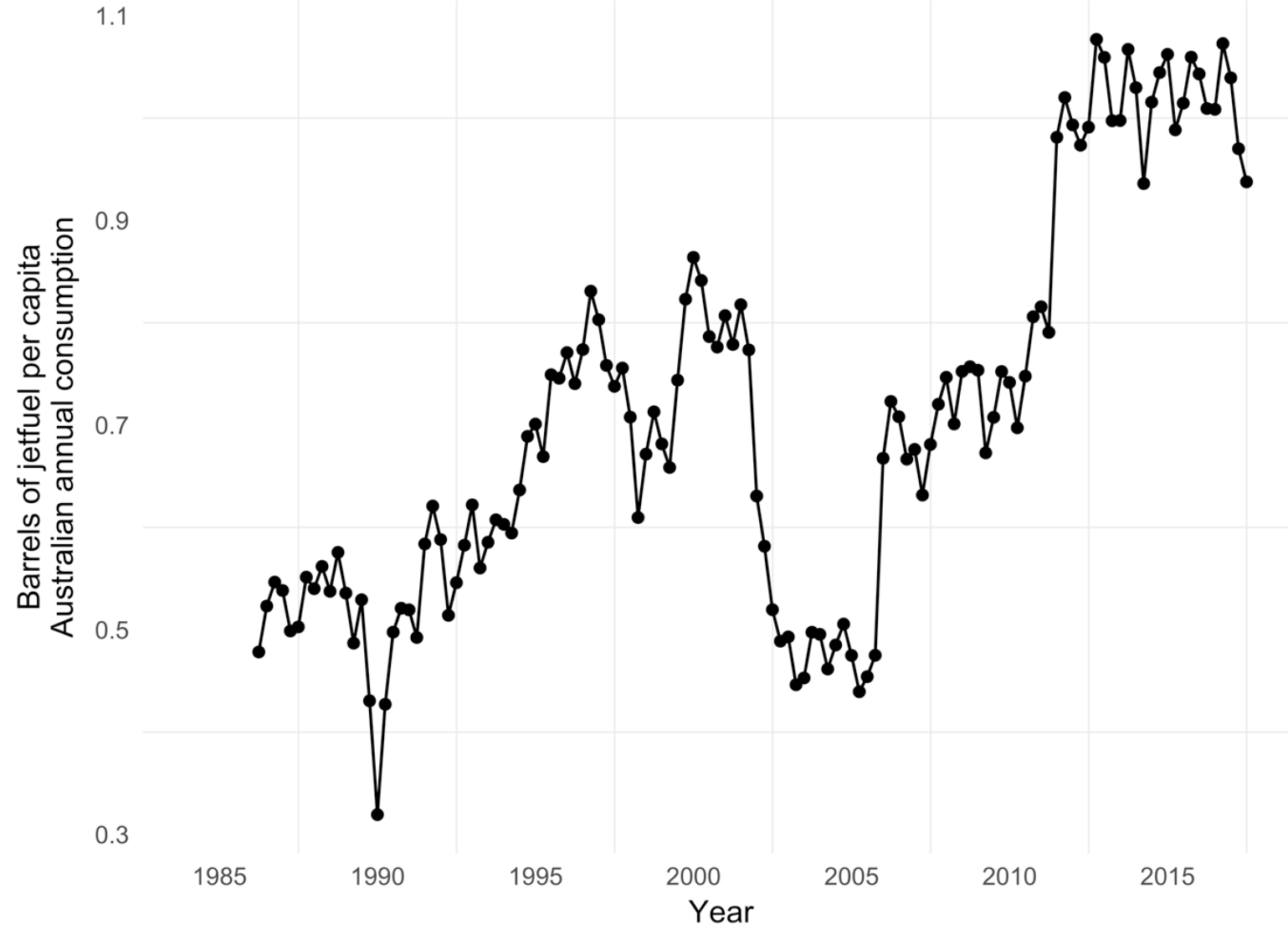

Figure 1: Barrels of aviation turbine fuel consumed for Australian domestic aviation per capita per quarter, 1984 - 2017. Source: Created by the authors from Australian Petroleum Statistics (Department of the Environment and Energy, 2017) and Australian Demographic Statistics (Australian Bureau of Statistics, 2017a).

Aviation is likely to comprise a rapidly growing share of greenhouse gas emissions. For example, a study of the UK found that even a moderate growth in aviation emissions would exhaust the entire carbon 2050 budget for the UK consistent with atmospheric $\mathrm{CO}_{2}$ levels of 450 parts per million (ppm) (Bows et al., 2006). As such, it is unlikely that aviation greenhouse gas emissions will be stabilised at levels consistent with risk-averse climate targets without measures that actively reduce aviation demand or restrict flying (Macintosh and Wallace, 2009). The intractable nature of the air travel emissions problem is reflected in its ongoing exclusion from global climate change instruments. The only meaningful policy option appears to be some market-based mechanism (MBM) that prices carbon emissions.

\subsection{Carbon pricing and aviation}

At the global scale, carbon pricing has been identified as the key policy mechanism available to governments to reduce greenhouse gas emissions (World Bank, 2014). Indeed, establishing a carbon price through taxation, emissions trading, or regulation has been described as 'the first task of mitigation policy' (Stern, 2006: 35). Carbon pricing requires emitters to be financially accountable for the environmental cost of emissions and provides an incentive to invest in new technologies that might reduce global warming. In general, a carbon price increases the costs of carbon-based production, therefore decreasing demand or leading to substitution between technologies or products. However, in the case of air travel, where the 
replacement of aircraft fleets is an expensive long-term response, any initial effect of carbon pricing is likely to be exhibited in decreased travel demand. Consequently, an effective carbon price should theoretically reduce aviation emissions by increasing prices and thereby reducing demand.

A MBM for greenhouse gas emissions is the preferred international approach. The framework for current global policy is provided by the International Civil Aviation Organization (ICAO), an agency of the United Nations established in 1944 to manage and govern the Convention on International Civil Aviation (i.e. the Chicago Convention) across its 192 member states (https://www.icao.int). In 2013, ICAO member states announced that they would cooperate to achieve 'carbon-neutral growth' by 2020 (CNG2020). The CNG2O20 agreement advanced an aspirational set of targets, including $1.5 \%$ average annual fuel efficiency improvement between 2010 and 2020, carbon neutral growth from 2020, and a reduction of $50 \%$ in net emissions by 2050 compared to 2005 levels. Many measures were initially considered including a cap-and-trade scheme similar to the EU Emissions Trading System (EU ETS), but member states eventually decided on a global carbon offsetting scheme to reach the goal through emission reduction projects in other sectors (Carbon Market Watch, 2016).

This scheme was ratified by 39th ICAO Assembly on October 6, 2016. Member states finalized the details of a MBM to offset most of the $\mathrm{CO}_{2}$ growth in aviation from 2020 onwards. The measure, known as the Carbon Offsetting and Reduction Scheme for International Aviation (CORSIA), marks the first time a MBM covers an entire international sector. Under CORSIA, airlines from participating member states are assigned individual emission limits according to their international aviation emissions, calculated based on the average international emissions for the 2019-2020 period. If an airline's emissions exceed this limit, the airline must then buy emission rights. These are to be met by the purchase of qualifying credits from other industries and projects that limit GHG emissions (i.e. a cross-sectorial model).

CORSIA will be implemented in three stages. The pilot (2021-2023) and the first phase (20242026) are both voluntary. As of 31 January 2018, 73 states representing $88 \%$ of total international civil aviation transport have indicated they will volunteer. The second phase (2027-2035) is mandated and includes all states with an individual share of international aviation activity in year 2018 above $0.5 \%$ of total activity or whose cumulative share reaches $90 \%$ of total activity (ICAO, 2017a). Developing countries are exempt unless they volunteer to participate. Important exclusions from the scheme are domestic aviation activity and the emissions of other climate pollutants from aviation (i.e. black carbon, nitrogen oxides, and the precursors of aviation-induced cloudiness).

According to modelling by the ICAO, the estimated quantity to be offset to achieve CNG 2020 would be 142-174 million tonnes of $\mathrm{CO}_{2}$ in 2025 and 443-596 million tonnes of $\mathrm{CO}_{2}$ in 2035 (ICAO, 2017b). The voluntary phases are expected to offset $64 \%$ of growth revenue tonne kilometres (RTKs) or $11 \%$ of all international RTKs based on the countries that have opted in thus far, whereas the mandatory phase will offset $75 \%$ of growth RTKs or $32 \%$ of total international RTKs. Between 2021 and 2035, the MBM is expected to cover approximately $73 \%$ of growth RTKs and $25 \%$ of all international RTKs (ICAO, 2017c). 
In 2013, the trade association for the world's civil airlines, the International Air Transport Association (IATA), committed to the CNG2O20 target with certain caveats. These included the necessity for ICAO to work with industry, particularly in terms of research and development, to produce cheaper biofuels and more efficient aircraft as part of a broader voluntary package of initiatives in which a MBM is only used as a complement to close any gap between emissions and the CNG2O20 aspirational goal. In addition, the industry strongly urged ICAO to develop a single global MBM that avoids "a patchwork of unilateral national and/or regional policy measures" (IATA, 2013).

Critics of CORSIA have argues the scheme is fundamentally flawed because of low participation (including voluntary stages, multiple exclusions, and disregard of domestic aviation), weak mandates (i.e. aspirational goals with few sanctions for non-compliance), and a failure to limit or reduce emissions at source (i.e. using carbon rights from other industries to offset increasing aviation emissions) (Scott et al., 2016; Becken and Mackey, 2017; Higham et al., 2018). Indeed, predictive modelling studies of the likely outcomes of CORSIA have suggested the scheme is likely to be ineffectual even if fully applied. Cui and Li (2017b) analysed the influence of the CNG2O2O strategy on airline efficiency using predictions based on empirical data from 29 global airlines, including seven ranked top 10 in the world on passenger turnover volume. The study concluded that 'most airlines' efficiencies have little change when the CNG2020 strategy is considered' (Cui and Li, 2017b: 1297). Although the impacts of the CNG2O2O strategy were small, the study found some differences in the efficiency change among airlines. For instance, airlines whose emissions were lower than the limits imposed increased total revenue through the sale of emission rights, whereas airlines whose emissions were higher larger than the limits would face increased operation expenses through the purchase of emissions rights. The study did not, however, consider the airlines' capacity to pass on costs to passengers.

$\mathrm{Li}$ and Cui (2017) analysed the impacts of the CNG2O2O strategy on airline environmental inefficiency based on the predictive data from the 29 airlines used by Cui and $\mathrm{Li}$ (2017b). This analysis concluded that most airlines' overall inefficiencies decline when the CNG2O2O strategy is applied, indicating a positive effect on efficiency improvement. Further, Cui \& $\mathrm{Li}$ (2017a) developed a dynamic model of airline efficiency (again with the same set of airlines) and found the efficiency of pollution-causing inputs (in this case aviation kerosene) to be a more important determinant of overall efficiency change than the CNG2O2O strategy. Under this modelled scenario the airlines included in the study would be unable to meet the requirement of the CNG2020 strategy at the current rate of emission growth (Cui and $\mathrm{Li}$, 2017a).

While these analyses are useful, they are based on scenario modelling of future events. Little is known in practice about the effectiveness of carbon pricing as a means of reducing aviation emissions when applied to existing real-world schemes. The most prominent example of aviation carbon pricing is the EU ETS. This constitutes the world's largest carbon pricing scheme and is active in thirty European countries. Aviation emissions were accommodated in the EU ETS from the start of 2012, but enforcement was suspended for all flights to and from non-EU countries to allow for a carbon pricing mechanism for international air travel to be negotiated. The EU ETS continues to cover all flights within and between the EU ETS signatory 
states (Anger, 2014). While several studies have estimated the effect of the EU ETS on travel demand, these are largely simulations of predicted behavior based on proposed ETS rules that rely on strong assumptions regarding cost pass-through rates and demand elasticities (see Anger and Köhler, 2010). Similarly, the evaluations of carbon pricing schemes that have been undertaken in other jurisdictions tend to take the approach of modelling proposed scenarios rather than estimating observed impacts (e.g. Mayor and Tol, 2007). The few studies of actual air travel do suggest that carbon pricing may fail to curb aviation emissions in practice. For example, a series of studies on the introductory period of the EU ETS 2008-2012 found that the scheme did not significantly affect airline performance (Cui et al., 2016a), had little influence on pollution abatement costs (Cui et al., 2017), and witnessed a decrease in overall airline efficiency (Cui et al., 2016b). More studies of actual travel behaviour in response to carbon pricing are required if the effectiveness of carbon pricing in reducing airline emissions is to be assessed.

The aim of this paper is to empirically assess one such measure - the price that was levied in Australia between 2012 and 2014 on greenhouse gas emissions from large-scale industry, termed the Clean Energy Future (CEF) policy - in terms of its effectiveness in reducing aviation emissions. The introduction and eventual abolition of the CEF package presents the opportunity to contribute to the limited literature evaluating the specific effect of carbon pricing on aviation emissions. The $\mathrm{CEF}$ imposed a price on carbon-dioxide equivalent $\left(\mathrm{CO}_{2}-\mathrm{e}\right)$ greenhouse gas emissions for the first time in Australia. During the period of its truncated implementation, the policy included a levy of \$23AUD per tonne of $\mathrm{CO}_{2}$-e emitted from July 2012 to June 2013 and $\$ 24.15$ per tonne from July 2013 to June 2014. To simplify implementation, only the largest corporations $(n=349$ in 2012-13) emitting at least 25,000 tonnes of $\mathrm{CO}_{2}$-e per year were liable to pay the carbon price (Clean Energy Regulator, 2012). This encompassed around 60\% of emissions in the Australian economy (Jotzo, 2012) and included domestic aviation for Australia's two largest domestic carriers, QANTAS (and its wholly-owned subsidiary, the low-cost domestic airline Jetstar) and Virgin Australia, who collectively accounted for 92\% of domestic seat kilometres flown (BITRE, 2017a; Virgin Australia, 2013; Qantas, 2013). The CEF policy was repealed from the $1^{\text {st }}$ July 2014 following a change of federal government.

The introduction and subsequent abolition of this carbon price on domestic aviation in Australia allows us to analyse the impact of carbon pricing on travel demand using actual air travel data. Specifically, in this study, the temporal association of the carbon price with Australian domestic RPKs per capita is estimated. RPKs per capita are not a direct measure of aviation emissions, but provide a proxy measure of consumers' behavioural responses to the introduction of carbon pricing. The association between RPKs and the carbon price is adjusted for the cost of fuel, cost of labour, per capita gross domestic product (GDP) and a measure of airline competition strategies at the time. 


\section{Study context - Australian carbon price and the aviation sector $2012-2014$}

Air travel within Australia is structured by the country's urban spatial system, as measured in terms of population and employment distribution (Fuellhart and O'Connor, 2013). Sydney and Melbourne dominate the system as measured by total domestic seat capacity and number of routes, followed by Brisbane and Perth. There is some variation in services between routes due to the regional distribution of the aviation-dependent mining and tourism industries, and the emergence of monopoly power on some associated routes, but this general pattern is relatively stable over time (Fuellhart and O'Connor, 2013).

\subsection{Airfare pricing 2012-2014}

Air ticket prices have tended to fluctuate markedly over particular periods in the development of the domestic industry. Figure 2 and Table 1 summarise changes in domestic air fares from 1992 to 2017 using the Bureau of Infrastructure, Transport and Regional Economics (BITRE) domestic air fare index. The BITRE's domestic air fare index is a price index of real domestic airfares over time, using prices collected from a travel agent reservation system (prior to 2003) and the internet (from 2003 onwards). Prices are collected for the lowest available fare in each fare class, weighted over selected routes. The units of the index are unimportant to their interpretation, because the index seeks to highlight changes in relative prices for several routes (see BITRE, 2017b).

Figure 2 and Table 1 show that real prices for best discount fares have varied markedly, including during the period of the carbon price (the time period shaded in figure 2). Best discount fares finished the CEF period at the same level they started, although they did increase during 2013. These discounted prices were highly volatile, changing by an average of 10.6 index points from month-to-month during the CEF period. Discount prices stabilized noticeably after the abolition of the carbon price. Following a steep fall in 2011, business class and economy fares have both slowly increased. Business class fares displayed substantial variation during the period of the carbon price, with an average change in index prices from month-to-month of 6.6 points, compared with 2.4 points prior to the carbon price and 1.1 points after the removal of the price. The price of restricted economy fares was much more stable from month-to-month, despite a consistent trend of increasing real fares since 2011. In short, none of the price series exhibited a clear or obvious increase during the CEF period, although this may have been obscured due to increased volatility of prices during this period. 


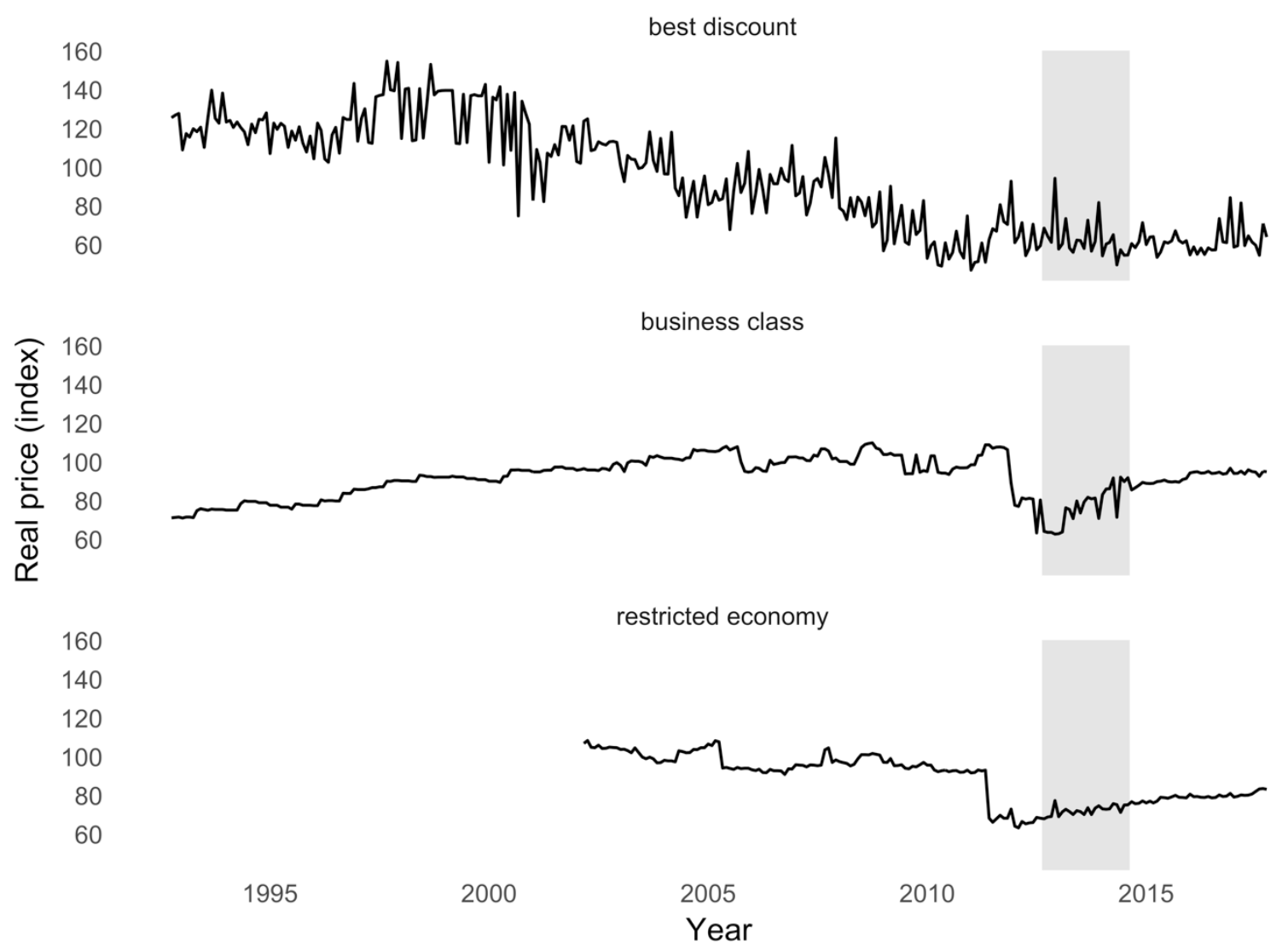

Figure 2. Period of the 'Clean Energy Future' policy and the Australian domestic airfare index $1992-2017$. Source: Domestic Air Fare Indexes (BITRE, 2017b)

A consideration of prices is important because price is the mechanism or 'signal' through which increased production costs may be translated into demand, which in turn may be expected to influence carbon emissions. Given price signals are most likely to affect the behavior of consumers with elastic demand curves, understanding the drivers of discount fares may give us insights into the likely covariates of a carbon price. A study by Fuellhart et al. (2015), which used linear modelling to predict best discount fares on 24 major Australian domestic routes, found that prices had clear geographical correlates $\left(\mathrm{R}^{2}=87.7 \%\right)$, including (in order of effect) flight distance, presence of a small city on the route (reducing competition), number of connections between origin and destination cities, the presence of low-cost carriers (LCCs) on the route (increasing competition), and the presence of regional economic activity (especially mining). In summary, airfare price, at least at the aggregate level, proved to be well predicted by the costs of production (i.e. the production cost for the distance travelled for an aircraft) plus a series of competitive effects born of the spatial structure of the industry.

However, there is another influence on prices in play here. Prices vary considerably within flights on particular routes - a variation termed 'price dispersion'. In order to match price to the elasticities of consumer demand, airlines offer multiple and dynamic fares on a single flight by varying tickets by class, travel conditions, and time of booking (De Roos et al., 2010). This price dispersion on Australian domestic routes is most evident where QANTAS and Virgin compete as full-cost carriers, and is lowest on routes that are serviced by competing LCCs (De Roos et al., 2010). Beyond this, the whole dynamic may be affected by the strategic interaction between airlines. Airlines clearly do act in seemingly irrational ways in the short term in order 
to attempt to secure longer-term competitive advantage in an extraordinarily highlyconcentrated industry.

Table 1. Airline prices before, during and after the Clean Energy Future period, reported in the Domestic Air Fare Indexes. Source: Domestic Air Fare Indexes (BITRE, 2017b)

\begin{tabular}{|c|c|c|c|}
\hline \multirow[b]{2}{*}{ Period } & \multicolumn{3}{|c|}{ Best discount } \\
\hline & Before $^{1}$ & During ${ }^{2}$ & After $^{3}$ \\
\hline Mean & 63.2 & 63.2 & 61.8 \\
\hline First month price & 52.7 & 57.5 & 54.7 \\
\hline Last month price & 70.7 & 57.5 & 64.1 \\
\hline \multirow{3}{*}{$\begin{array}{l}\text { Standard deviation } \\
\text { Mean absolute monthly } \\
\text { difference }\end{array}$} & 10.9 & 9.5 & 6.7 \\
\hline & 10.5 & 10.8 & 6.6 \\
\hline & \multicolumn{3}{|c|}{ Business class } \\
\hline Period & Before & During & After \\
\hline Mean & 96.2 & 75.4 & 92.4 \\
\hline First month price & 93.7 & 63.5 & 90.0 \\
\hline Last month price & 81.0 & 92.3 & 95.1 \\
\hline \multirow{3}{*}{$\begin{array}{l}\text { Standard deviation } \\
\text { Mean absolute monthly } \\
\text { difference }\end{array}$} & 10.9 & 9.5 & 2.9 \\
\hline & 2.4 & 6.6 & 1.1 \\
\hline & \multicolumn{3}{|c|}{ Restricted economy } \\
\hline Period & Before & During & After \\
\hline Mean & 78.9 & 71.9 & 79.2 \\
\hline First month price & 92.4 & 68.8 & 75.2 \\
\hline Last month price & 66.2 & 71.4 & 83.3 \\
\hline $\begin{array}{l}\text { Standard deviation } \\
\text { Mean absolute monthly }\end{array}$ & 13.0 & 2.5 & 2.1 \\
\hline difference & 2.5 & 2.2 & 0.7 \\
\hline
\end{tabular}

\subsection{Airline capacity 2012-2014}

This notion of price irrationality is particularly important for our analysis because the period leading up to the CEF was characterised by increasing competition between Qantas and Virgin, with both airlines attempting to capitalise on the collapse of Ansett airlines, a major domestic provider, in 2001. The competition between members of the remaining duopoly reached its zenith at the time of the CEF. Qantas's strategy was to aggressively defend a specific market share target (i.e. 65\%) on all competitive routes against a sustained campaign by Virgin to win new customers in what became popularly known as the airline 'capacity wars' (Janda, 2014). This competitive strategy resulted in the airlines running flights at well below profitable passenger loads. Figure 3 shows the marked decline in domestic passenger load by several percentage points during the carbon price period. These capacity reductions largely eliminated 
profitability. In 2014 Qantas reported \$2.8AUD billion (Qantas, 2014) and Virgin \$356AUD million (Virgin Australia, 2014) annual losses. While these losses were in part attributable to increasing fuel prices and costs of ageing fleet replacement, the 'capacity wars' took a heavy toll on both sides.

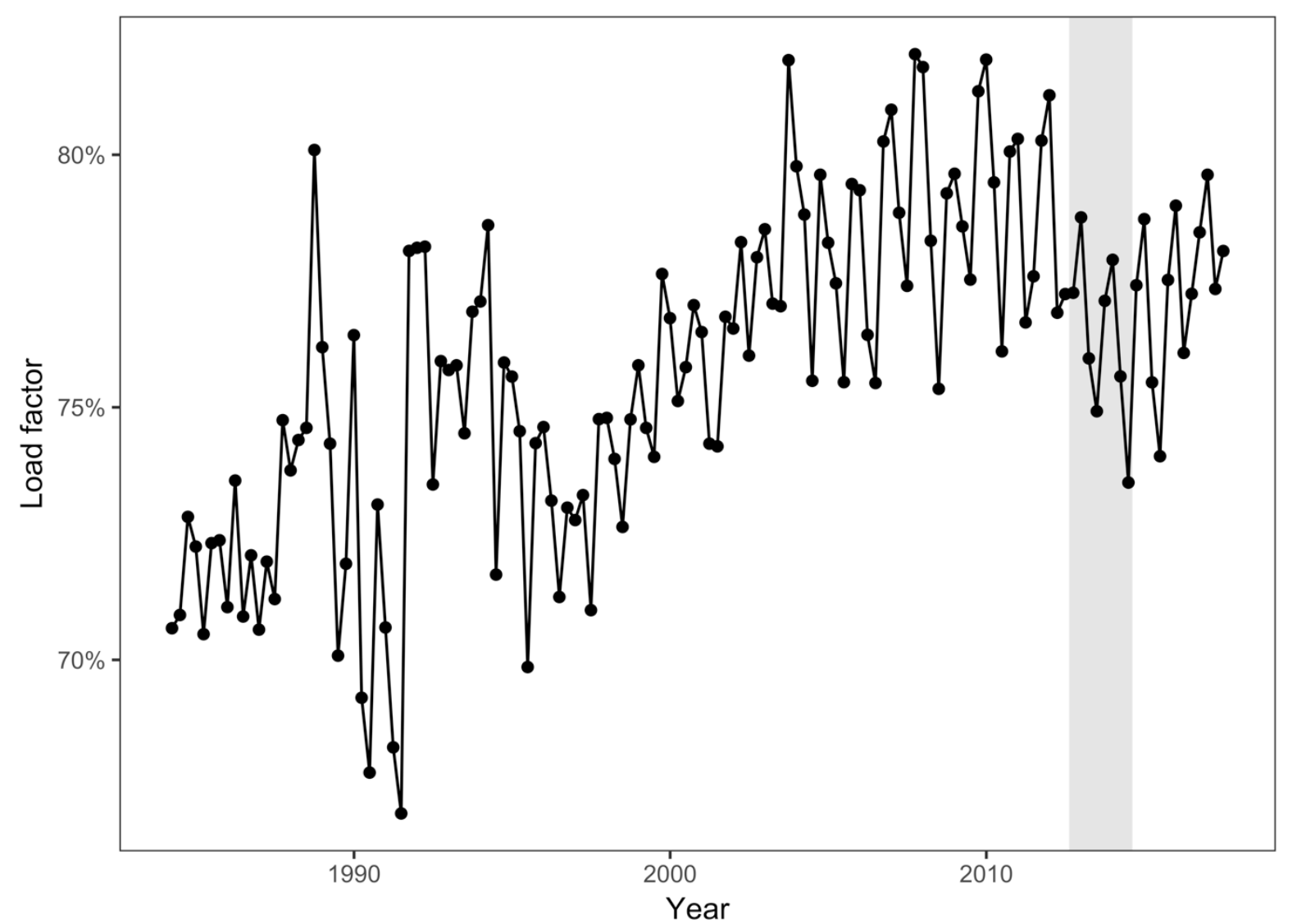

Figure 3. Domestic load factor Australian domestic passenger aviation 1984-2017. Source: Monthly Airline Performance (BITRE, 2017c)

\subsection{Pass-through of the carbon price}

Given this evidence of apparently irrational behaviour on the part of the airlines, the passthrough rate of the CEF (the degree to which carbon pricing costs were passed onto consumers in increased final prices) is somewhat unclear. There remains the possibility that the effects of the carbon price may have been internalised, and hence not affected demand or subsequent emissions. If for some reason the price was not passed on (such as due to internalization of the price by businesses, discounting, short-term irrational pricing aimed at longer-term competitive advantage), then it can have no direct behavioural effect. Therefore, before a meaningful analysis of the behavioural response to the carbon price can be conducted, the incidence of the price on the consumer, at least to some degree, needs to be established.

The airlines claimed to have passed the price through, and even blamed their losses in part on its introduction. QANTAS and Virgin Australia reported that the introduction of the carbon price drove up operating expenses by \$106AUD million (0.7\%) and \$48AUD million (1.2\%) respectively in 2012-13 (Qantas, 2013; Virgin Australia, 2013). These increased operating costs equated to between $\$ 1.82 \mathrm{AUD}$ to $\$ 6.86 \mathrm{AUD}$ per fare, depending on route (Surgenor, 2014). 
However, doubt was raised about this claim when the airlines failed to reduce fares upon repeal of the price in 2014. At this point, the Australian Competition and Consumer Commission (ACCC) stepped in to investigate the possibility of anti-competitive practice by the airlines. The ACCC was of the opinion that the airlines did initially pass on the costs of the price, although this pass-through may have declined over time due to competitive pressures. In its Ministerial report, the ACCC argued that 'the airlines attempted to recover the cost of the carbon price by increasing their airfares and were likely to have had some, albeit limited, success in recovering these costs in the period immediately after these fare increases were applied. However, the ACCC considered these fare increases were likely to have been transitory, and not enduring over the period that the carbon price was in effect due to issues including significant passenger capacity increases during the period' (Australian Competition and Consumer Commission, 2015: 17). It may be concluded that the carbon price was passed on to a degree, but that price pass-through was attenuated by the airlines' competitive strategies, especially flying aircraft and routes at low capacities.

\subsection{The carbon price and demand increase}

The policy measures comprising CEF may also have, in a countervailing direction, acted to stimulate the domestic demand for air travel. The policy package included measures that increased household incomes, targeted at low- and middle-income households and delivered through the tax and transfer system. These 'household assistance' measures included: a 1.7\% increase in several government transfer payments commencing in May 2012; an increase in the threshold at which personal income tax began to be levied, rising from $\$ 6,000$ to $\$ 18,200$ per annum, commencing July 2012; and several other less substantial measures (Australian Government, 2013). These measures are an important consideration when evaluating the effectiveness of the carbon price as additional household disposable income may have stimulated demand for air travel and needs to be included in the analysis. Similarly, the flowon effect of increased household consumption could increase the demand for business travel which is more profitable (Table 1) and similarly needs to be considered in multivariate modelling.

\section{Method}

\subsection{Data}

Data on the outcome variable, monthly Revenue Passenger Kilometres (RPKs) for domestic travel in Australia from January 1984 to June 2017, were obtained from the Bureau of Infrastructure, Transport and Regional Economics (BITRE, 2017c). A revenue passenger kilometre is defined as a kilometre of domestic air travel by a paying passenger (i.e. travel by aircrew is excluded). RPKs were converted to RPKs per capita, using quarterly Australian estimated residential population (ERP) data from the Australian Bureau of Statistics (Australian Bureau of Statistics, 2017a). Because the covariate series included in the model 
had a quarterly frequency and covered a shorter time period than the RPK series, the RPK series was truncated to conclude in June 2017 and was aggregated into quarters.

The two most important drivers of domestic air travel demand are income available to households and businesses, and the price of travel (Lim, 2006; Wang and Song, 2010). Because the carbon price was intended to affect both the price of air travel (through the carbon price) and income (through the household assistance package) both constructs may confound the analysis if not included in the model. Real Gross Domestic Product (GDP) per capita was chosen as a proxy for both business activity and household income. While a model including separate series for real per capita household disposable income and real per capita industrial production was tested, the model including only GDP demonstrated superior model fit on both the Akaike's Information Criterion and adjusted $R^{2}$ metrics. All tested income series were sourced from the Australian National Accounts (Australian Bureau of Statistics, 2017b) adjusted for inflation using the Consumer Price Index (Australian Bureau of Statistics, 2017d) and converted into per capita terms using the ERP series.

Two series were constructed to represent the most important components of the cost of air travel production, cost of fuel per available seat kilometre (ASK) and cost of labour per ASK. These two variables were selected as they are the two largest determinants of the cost of air travel production, accounting for a combined $51 \%$ of operating expenses for both major airlines in the 2012-2013 financial year (Qantas Airways Limited, 2013; Virgin Australia, 2013). The cost of fuel in 2017 Australian dollars was estimated by obtaining the monthly Cushing Crude Oil Future Contract 1 price (International Monetary Fund, 2017), converting it from US dollars to Australian dollars using historical exchange rates (Reserve Bank of Australia, 2017) and then adjusting for CPI. The Cushing futures price was selected as it smooths over some of the extreme volatility evident in oil prices over the period of interest, although the substitution of the futures price with the spot price (e.g. Brent crude) does not substantively alter the results of the analysis. This series was converted from real dollars per barrel to real dollars per ASK through conversion into a fuel cost for domestic air travel using the total amount of domestic aviation fuel (both turbine fuel and aviation gasoline) consumed in Australia during this period and then dividing by the number of quarterly ASKs. The real cost of labour was estimated by multiplying the number of persons estimated to be working in the air and space transportation industries each quarter (Australian Bureau of Statistics, 2017e) by the total average weekly earnings in that quarter (Australian Bureau of Statistics, 2017c), with both employed persons and earnings accounted for separately for men and women. Average weekly earnings were used as no data series was available estimating wages specifically in the aviation industry that dates to 1984 . This estimated wages bill was adjusted to 2017 dollars using the CPI and divided by the number of quarterly ASKs to calculate the cost of labour per ASK. In addition, to account for competitive effects between airlines an additional covariate, airline capacity, measured in terms of total available seat kilometres flown (BITRE, 2017c), was selected for inclusion into the modelling process.

Dummy variables were created to account for exogenous shocks. Four exogenous shocks were selected for inclusion on the basis of an examination of the residuals of the regression model. First was the occurrence of the World Exposition in Brisbane in 1988. This was the largest event comprising Australia's bicentennial celebrations and attracted over 15 million visitors 
and generated an estimated 1.2 million domestic flights (Faulkner, 2003). Second was major industrial action by Australian Federation of Air Pilots in 1989 who campaigned fiercely for a $30 \%$ wage increase. Locally knows as the 'pilots strike', this militant action was one of the most dramatic and costly in Australian industrial relations history resulting in the 'almost complete interruption of domestic airline transport' (Bray and Wailes, 1999). Third was a price war that commenced immediately after Australia's domestic aviation industry was deregulated in November 1990. A single new entrant to the market, Compass Airlines, triggered a 12-month price war with the two existing airlines that resulted in fare discounting of up to $70 \%$ (Douglas, 1993). Compass was grounded by its creditors in December 1991. Fourth was the collapse of the major domestic carrier Ansett Airlines in September 2001, then Australia's second largest airline, causing around 30\% of flights to be cancelled in Australia's largest airports (Leiper, 2002).

\subsection{Statistical analysis}

A time-series regression analysis was conducted to estimate the association between the carbon price and per capita domestic RPKs. All continuous variables were log transformed to stabilise their variance. Because the log transformed outcome variable displayed evidence of a unit root, first differences were taken of the outcome variable and continuous co-variates. Independent variables were entered into the model with two lagged regressors. Although cross-correlations were tested at up to four lags, two lags provided the best model fit.

Two models were fit to estimate the effect of the carbon price on per capita RPKs. Model 1 estimated a step change in per capita RPKs, that is, a sustained, once-off change in RPKs. Model 2 estimated a change in the slope of per capita RPKs, that is, a change in the rate of growth of per capita RPKs. The following model was optimised using Ordinary Least Squares:

$$
\begin{aligned}
& \Delta \ln R P K_{t}=c+\beta_{1} t+\beta_{2} \Delta \ln G D P_{t}+\beta_{3} \Delta \ln G D P_{t-1}+\beta_{4} \Delta \ln G D P_{t-2}+\beta_{5} \Delta \ln F U E L_{t} \\
& +\beta_{6} \Delta \ln F U E L_{t-1}+\beta_{7} \Delta \ln F U E L_{t-2}+\beta_{6} \Delta \ln L A B O U R_{t} \\
& +\beta_{7} \Delta \ln L A B O U R_{t-1}+\beta_{8} \Delta \ln L A B O U R_{t-2}+\beta_{9} E X P O_{t}+\beta_{10} E X P O_{t-1} \\
& +\beta_{11} E X P O_{t-2}+\beta_{12} S T R I K E_{t}+\beta_{13} S T R I K E_{t-1}+\beta_{14} S T R I K E_{t-2} \\
& +\beta_{15} \text { PRICEWAR }+\beta_{16} \text { PRICEWAR }_{t-1}+\beta_{17} \text { PRICEWAR }_{t-2} \\
& +\beta_{18} \text { ANSETT }_{t}+\beta_{19} \text { ANSETT }_{t-1}+\beta_{20} \text { ANSETT }_{t-2}+\beta_{21} J U N_{t}+\beta_{22} \text { SEP }_{t} \\
& +\beta_{22} D E C_{t}+\beta_{23} C A R B O N P R I C E_{t}^{i}+\varepsilon_{t}
\end{aligned}
$$

where $R P K_{t}$ is per capita RPKs at time $t, c$ is a constant, $G D P_{t}$ is per capita gross domestic product in real 2014 Australian dollars at time $t, F U E L_{t}$ is the price of Cushing Oklahoma oil futures contract 1 per ASK in real 2017 Australian dollars at time $t, L A B O U R_{t}$ is the price of air and space transport labour per ASK in real 2017 Australian dollars at time $t, E X P O_{t}$ is a dummy variable indicating the World Exposition in Brisbane in the quarter ending September 1988, $S T R I K E_{t}$ is a dummy variable indicating the Pilot's Dispute in the quarter ending September 1989, PRICEWAR $R_{t}$ is a dummy variable indicating the climax of the Compass Airlines price war in the quarter ending September 1991, $A N S E T T_{t}$ is a dummy variable indicating the collapse of Ansett Airlines in the quarter ending September 2001, $J U N_{t}, S E P_{t}$, and $D E C_{t}$ are dummy variables indicating a quarter ending June, September or December respectively, and 
CARBONPRICE $E_{t}{ }^{i}$ is a dummy variable to estimate the effect of the carbon price for model $i$ (if $i=1, C A R B O N P R I C E=1$ for the September 2012 quarter, otherwise 0 ; else if $i=2$, CARBONPRICE $=1$ from the September 2012 quarter to June 2014 quarter, otherwise o).

Because the effect of the CEF may have been ameliorated by the capacity wars that occurred at a similar time, we also fitted a second set of models that incorporated an additional covariate, capacity, measured in terms of total available seat kilometres flown. This capacity variable (i.e. total available seats) is not included in Models 1 and 2 as it presents long-run endogeneity problems given capacity responds to demand and demand responds to capacity. However, the behaviour of Australia's two largest airlines during the 'capacity war' may have led capacity and demand to diverge for several quarters. Consequently, Models 3 and 4 include capacity as a covariate to determine if this specification changes the estimated association between demand and the CEF.

\section{Results}

Quarterly per capita domestic RPKs in Australia increased from $155 \mathrm{~km}$ in January-March 1984 to a peak of $756 \mathrm{~km}$ in the final quarter of 2013, before declining to $677 \mathrm{~km}$ in April-June 2017 (Figure 4). Domestic air travel is highly seasonal, with RPKs increasing in the second half of the year. Air travel is influenced by external shocks including industrial action, airline collapses, one-off tourism events and heavy price discounting. Although air travel in Australia tends to recover somewhat after such shocks, the Augmented Dickey-Fuller test $(D F=-2.5, p$ $=0.35)$, Kwiatkowski-Phillips-Schmidt-Shin test $(K P S S=0.41, p=0.01)$ and Phillips-Perron test $\left(M Z_{a}-13.7, p=0.32\right)$ all indicate the presence of a unit root, suggesting that external shocks have a lasting effect on the amount of air travel undertaken. 


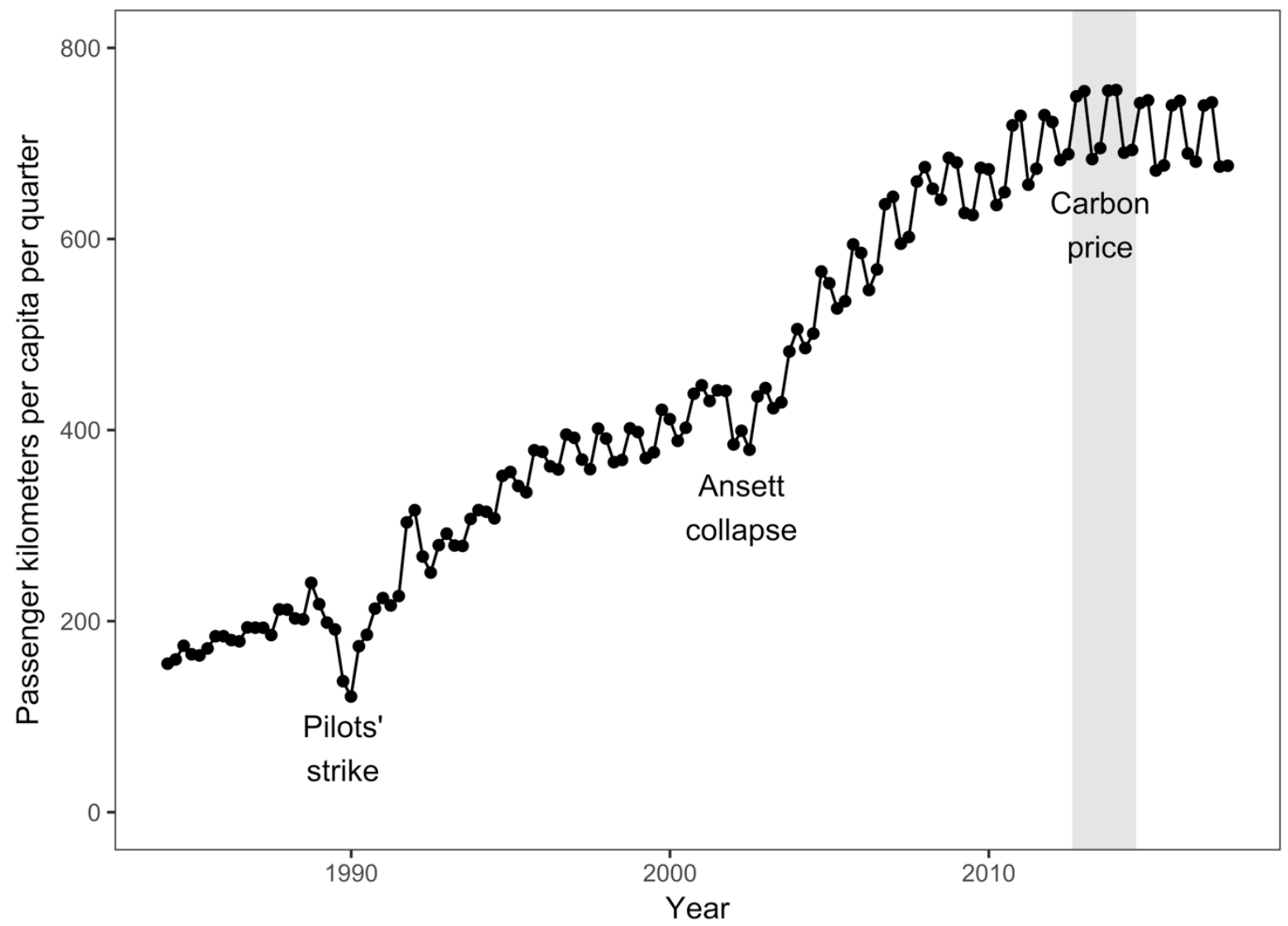

Figure 4. Quarterly domestic per capita revenue passenger kilometres travelled in Australia, $1984-2017$. Duration of the carbon price and important external shocks are labelled.

There was no statistically significant association between the introduction of the \$23.00AUD (FY 2012) to \$24.15AUD (FY2013) per tonne carbon price and per capita domestic passenger kilometres travelled (Table 2). Two transfer functions were estimated, one in which the carbon price resulted in a step-change in the consumption of air travel (Models 1 and 3) and one in which the carbon price changed the rate at which per capita domestic air travel was increasing (Models 2 and 4). For each of these transfer functions, two models were fitted, one pair excluding the capacity variable (Models 1 and 2) and one pair including it (Models 3 and 4). The carbon price indicator variable was not significantly associated with per capita domestic passenger kilometres in any of these four models. 
Table 2. Ordinary Least Squared regression models of the association between the carbon price and per capita Revenue Passenger Kilometres

\begin{tabular}{|c|c|c|c|c|}
\hline & Model 1 & Model 2 & Model 3 & Model 4 \\
\hline Constant & $-0.04(-0.05,-0.02)$ & $-0.04(-0.05,-0.02)$ & $-0.04(-0.05,-0.02)$ & $-0.04(-0.05,-0.02)$ \\
\hline $\mathrm{T}$ & $-0.00(-0.00,-0.00)$ & $-0.00(-0.00,-0.00)$ & $-0.00(-0.00,0.00)$ & $-0.00(-0.00,0.00)$ \\
\hline JUN & $0.05(0.03,0.06)$ & $0.05(0.03,0.06)$ & $0.02(0.00,0.03)$ & $0.02(0.00,0.03)$ \\
\hline SEP & $0.15(0.14,0.17)$ & $0.15(0.14,0.17)$ & $0.10(0.08,0.11)$ & $0.10(0.08,0.12)$ \\
\hline DEC & $0.05(0.04,0.07)$ & $0.05(0.04,0.07)$ & $0.02(0.01,0.04)$ & $0.03(0.01,0.04)$ \\
\hline CARBONPRICE (level) & $0.00(-0.03,0.03)$ & & $-0.02(-0.04,0.01)$ & \\
\hline CARBONPRICE (slope) & & $-0.01(-0.02,0.01)$ & & $-0.01(-0.02,0.01)$ \\
\hline$\Delta / n(\mathrm{GDP})_{t}$ & $0.14(-0.17,0.44)$ & $0.12(-0.18,0.43)$ & $0.37(0.16,0.58)$ & $0.36(0.15,0.57)$ \\
\hline$\Delta \ln (\mathrm{GDP})_{t-1}$ & $-0.32(-0.62,-0.02)$ & $-0.34(-0.64,-0.04)$ & $-0.11(-0.32,0.10)$ & $-0.14(-0.35,0.08)$ \\
\hline$\Delta / n(\mathrm{GDP}) t-2$ & $0.05(-0.25,0.35)$ & $0.04(-0.27,0.34)$ & $0.15(-0.06,0.35)$ & $0.13(-0.08,0.33)$ \\
\hline$\Delta / n(\mathrm{FUEL}) t$ & $0.00(-0.03,0.03)$ & $0.00(-0.03,0.03)$ & $-0.01(-0.03,0.01)$ & $-0.01(-0.03,0.01)$ \\
\hline$\Delta / n$ (FUEL) $t-1$ & $-0.00(-0.03,0.02)$ & $-0.00(-0.03,0.02)$ & $-0.01(-0.03,0.01)$ & $-0.01(-0.03,0.01)$ \\
\hline$\Delta / n$ (FUEL) $t-2$ & $0.01(-0.02,0.04)$ & $0.01(-0.02,0.04)$ & $0.00(-0.02,0.02)$ & $0.00(-0.02,0.02)$ \\
\hline$\Delta / n(\text { LABOUR })_{t}$ & $-0.08(-0.12,-0.03)$ & $-0.08(-0.12,-0.03)$ & $-0.03(-0.07,0.00)$ & $-0.03(-0.07,0.00)$ \\
\hline$\Delta / n(\text { LABOUR })_{t-1}$ & $-0.02(-0.07,0.03)$ & $-0.02(-0.07,0.03)$ & $0.01(-0.03,0.04)$ & $0.01(-0.03,0.04)$ \\
\hline$\Delta / n(\text { LABOUR })_{t-2}$ & $-0.02(-0.07,0.03)$ & $-0.02(-0.07,0.03)$ & $0.01(-0.02,0.05)$ & $0.01(-0.02,0.04)$ \\
\hline$\Delta / n(\text { CAPACITY })_{t}$ & & & $0.64(0.50,0.77)$ & $0.62(0.48,0.75)$ \\
\hline$\Delta / n(\text { CAPACITY })_{t-1}$ & & & $0.10(0.04,0.16)$ & $0.10(0.04,0.16)$ \\
\hline$\Delta / n$ (CAPACITY $)_{t-2}$ & & & $0.08(0.02,0.14)$ & $0.08(0.02,0.13)$ \\
\hline ANSETT $_{t}$ & $-0.09(-0.14,-0.05)$ & $-0.10(-0.14,-0.05)$ & $-0.04(-0.08,-0.01)$ & $-0.04(-0.08,-0.01)$ \\
\hline ANSETT $_{t-1}$ & $-0.13(-0.18,-0.08)$ & $-0.13(-0.18,-0.08)$ & $-0.04(-0.08,-0.01)$ & $-0.05(-0.08,-0.01)$ \\
\hline ANSETT $_{t-2}$ & $0.09(0.04,0.14)$ & $0.09(0.04,0.13)$ & $0.07(0.03,0.10)$ & $0.07(0.03,0.10)$ \\
\hline PRICEWAR $_{t}$ & $0.18(0.13,0.23)$ & $0.18(0.13,0.23)$ & $0.14(0.10,0.17)$ & $0.14(0.10,0.17)$ \\
\hline PRICEWAR $_{t-1}$ & $0.01(-0.04,0.06)$ & $0.01(-0.04,0.05)$ & $0.00(-0.03,0.03)$ & $0.00(-0.03,0.03)$ \\
\hline PRICEWAR $_{t-2}$ & $-0.11(-0.16,-0.07)$ & $-0.11(-0.16,-0.06)$ & $-0.04(-0.07,0.00)$ & $-0.04(-0.07,0.00)$ \\
\hline $\mathrm{EXPO}_{t}$ & $0.06(0.01,0.11)$ & $0.06(0.01,0.11)$ & $0.04(0.01,0.08)$ & $0.04(0.01,0.08)$ \\
\hline $\mathrm{EXPO}_{t-1}$ & $-0.11(-0.16,-0.06)$ & $-0.11(-0.15,-0.06)$ & $-0.07(-0.11,-0.04)$ & $-0.07(-0.11,-0.04)$ \\
\hline
\end{tabular}




\begin{tabular}{|c|c|c|c|c|}
\hline $\mathrm{EXPO}_{t-2}$ & $-0.04(-0.08,0.01)$ & $-0.04(-0.08,0.01)$ & $-0.02(-0.05,0.01)$ & $-0.02(-0.05,0.01)$ \\
\hline STRIKE $_{t}$ & $-0.45(-0.49,-0.40)$ & $-0.45(-0.49,-0.40)$ & $-0.17(-0.23,-0.10)$ & $-0.17(-0.24,-0.11)$ \\
\hline STRIKE $_{t-1}$ & $-0.14(-0.19,-0.09)$ & $-0.14(-0.19,-0.09)$ & $0.04(-0.01,0.08)$ & $0.03(-0.01,0.08)$ \\
\hline STRIKE $_{t-2}$ & $0.40(0.35,0.45)$ & $0.40(0.35,0.45)$ & $0.15(0.06,0.23)$ & $0.16(0.07,0.24)$ \\
\hline Adjusted $\mathrm{R}^{2}$ & 0.926 & 0.927 & 0.967 & 0.966 \\
\hline Akaike's Information Criterion & -555.8 & -556.4 & -652.3 & -650.2 \\
\hline Jarque Bera Test $\chi^{2}$ & 2.2 & 2.3 & 31.9 & 26.1 \\
\hline Breusch-Pagan Test BP & 40.0 & 39.5 & 28.7 & 28.1 \\
\hline RESET $p$ & 0.82 & 0.97 & 0.82 & 0.82 \\
\hline
\end{tabular}

Notes: ${ }^{1}$ Bold typeface indicates that coefficients were significant, with $p<0.05$.

2 In indicates that the natural logarithm was taken for continuous variables (but not dummy variables) to stabilize variance. $\Delta$ indicates the first difference was taken for continuous variables because each of these series possessed a unit root. The suffixes $t, t-1$, and $t-2$ indicate data for the contemporaneous quarter, the previous quarter (i.e. one lag), and the quarter prior to that (i.e. two lags), respectively. 


\section{Discussion}

\subsection{Effectiveness of the Australian 'Clean Energy Future' policy}

The main contribution of this study is to demonstrate that the introduction of modest carbon prices is unlikely to substantially reduce domestic air travel. The study found no evidence to support the hypothesis that the introduction of a \$23.00AUD (FY 2012) to 24.15 (FY2013) per tonne of $\mathrm{CO}_{2}$ equivalent carbon price is associated with a reduction in domestic air travel. We suggest two reasons why the Australian 'Clean Energy Future' policy, July 2012 to June 2014, did not lead to reduced domestic aviation demand. First, the dependency of the aviation industry on a single fuel source means that switching to alternatives energy sources is not technologically feasible. This may be contrasted with stationary energy production and industrial consumption where the carbon price did have an effect. In the stationary energy sector, energy demand declined by 3.8 per cent and overall carbon emissions declined by 8.2 per cent compared to the two-year period before the carbon price (O'Gorman and Jotzo, 2014). One reason that the carbon price effectively reduced emissions from stationary energy is that stationary energy sources are substitutable as discussed earlier. While the stationary energy market can qualitatively adapt to price signals (e.g. by switching energy sources from coal to renewables), the aviation industry has thus far been limited to quantitative and incremental improvements in efficiency.

The second reason relates to the contingent peculiarities of the airline industry as it was operating in Australia at the time. The 'capacity wars' were an extreme form of duopoly competition that resulted in irrational pricing and enormous corporate losses. It is not entirely clear if the carbon price was passed through in its entirety, or if the pass-through lasted for the whole CEF period. The incidence of the price may have ended up with the airlines to some extent. In addition, oil prices were fluctuating wildly at this time, with the Brent crude spot price reaching above $\$$ US125/barrel. While the analysis adjusted for oil price movements in the multivariate modelling, the carbon price may have amounted to a small extra impost, hardly noticable by airlines and consumers in the context of these relatively large movements in oil prices. In short, the carbon price generated only a very small price signal in a very turbulent two-year period for the airline industry.

These findings are subject to several important qualifications. First, in Australia there is limited substitutability of domestic air travel relative to other developed countries where alternative travel modes (e.g. high speed rail) are available and countries are adjacent and much smaller. This may limit the generalizability of this study to contexts where the marginal time cost of substituting travel modes is lower. Second, while our model of the passenger kilometres fit the data well (adjusted R2 $=0.93-0.97$ ), an improved model specification may also improve the precision of estimates of the association with a carbon price. Third, despite disaggregating GDP into indicators of industrial production and household income, this study of aggregate outcomes was unable to distinguish between the countervailing effects of the carbon price increasing consumer prices and the compensation package increasing the purchasing power of households. Further microeconomic analysis of household income and 
expenditure surveys may be required to disentangle these effects. Fourth, these findings describe associations, not causation. Other unobserved influences on domestic air travel that occurred contemporaneously with the carbon price may have biased these estimates. However, given the satisfactory model fit and the use of independent variables that are the most important predictors of aviation demand, we doubt that this bias is likely to change the result of this study qualitatively.

\subsection{Policy Implications}

Air travel is closely associated with economic growth (Marazzo et al., 2010). Therefore, taxing airlines directly or using a MBM to increase the costs of production, and hence reduce GHC emissions, raises problems for other priorities in broader state economic policy. Indeed, macroeconomic performance is enhanced if the costs of air travel are lowered even marginally. A recent general equilibrium modelling study by PwC (2017) assessed the economic impact of abolishing air passenger taxes across the European Economic Area (EEA). The study found that the elimination of these taxes would lead to a real GDP increase of $0.07 \%$ in 2018 , sustained in both relative and absolute terms until 2030. This predicted growth is attributed to increased tourism expenditure and additional jobs (particularly in the aviation sector). Similarly, airports and related infrastructure are closely associated with macro-level economic growth (Blonigen and Cristea, 2012; Green, 2007; Sellner and Nagl, 2010) and regional development (Baker et al., 2015).

The tension between policy to control GHG emissions while maintaining the economic fortunes of states and regions acted as a key limitation of the CORSIA MBM. The failure of the scheme to restrict aviation emissions at source allows for their continued increase over time. Emissions reduction at source will depend on decisions of individual nation states or political regions (such as the EU). Despite the recognition by both ICAO and IATA that an international approach would be preferable to a number of ad hoc regional/national approaches, it appears that sub-global policy action is now both necessary and inevitable (Higham et al., 2018). To date, the EU ETS carbon pricing scheme remains the only concerted sub-global policy effort to address aviation emissions (Scheelhaase et al., 2018). Others at regional or national scales may be likely to follow. The results of this paper may usefully inform these future initiatives in three ways. First, a substantially higher carbon price than AUD 23-25 per tonne is necessary to reduce air travel demand and hence carbon emissions, particularly in comparable contexts where the opportunities for transport substitution are limited. However, further research is needed to understand the relationship between carbon price levels and RPKs flown in differing competitive contexts. Second, regulatory control of individual airlines may be necessary to prevent the passing on of costs to consumers, particularly in regions where transport substitutability is very low. Failure to do so may allow airlines to avoid the internalization of carbon costs, thus maintaining profit margins and poor environmental outcomes particularly in the context of rising air travel demand. Third, it will be necessary to implement policy interventions that account for the relationship between aviation and its economic correlates in other sectors of national and regional economies. For example, a study by Dwyer et al. (2013) of the potential economic effects of the CEF on the Australian tourism industry predicted a reduction in real GDP growth, real consumption, and employment (with declines 
in tourism employment greater than in relative terms than in other Australian industries) (Dwyer et al., 2013). Thus, carbon-pricing as a policy tool may require concomitant economic packages to offset change in other sectors of the economy.

\section{Conclusions}

There are several possible explanations for the failure of the carbon price to reduce domestic air travel. Simply adding a small impost to production costs is unlikely to be directly translated into fare prices because of: a) the pricing power of heavily concentrated aviation markets such as Australia; b) the relative volatility of fuel costs, the aviation industry's most significant cost, which means that air fares must necessarily be set in a manner that smooths out short-term changes in costs; and c) the magnitude of carbon price being far too low to effect measurable behaviour change. It is unclear to what extent each of these factors contributed toward the CEF's failure to significantly affect air travel.

The lack of behavioural response to a carbon price in the domestic aviation sector may be interpreted either positively or negatively. The positive interpretation observes that this is how a functional market-based mechanism is intended to operate - emissions reductions primarily take place in sectors where they are cheapest and easiest, while industries like aviation, where substitution towards low emissions alternatives is not currently feasibly, continue to pollute heavily. But this points toward the negative interpretation, which the authors favour. Aviation emissions need to be dramatically reduced if the air transport industry is in any sense to be considered environmentally sustainable. Consequently, the failure of the carbon price to substantially reduce RPK and aviation emissions appears to necessitate more coercive policy interventions. Business as usual in the aviation sector is incompatible with a habitable planet. This is one of the contradictions inherent in pricing mechanisms: even when they 'work', they do little to address emissions in the most intractable sectors. The behavioural change required to achieve necessary reductions in greenhouse gas emissions may require stronger and more coercive policy measures than modest carbon pricing alone. Further and detailed empirical analyses of the effectiveness of market-based and other GHG reduction strategies across multiple geographic scales and contexts are needed to design such policies. Ultimately, the entrenched contradiction between the economic and social benefits of air travel and its environmental consequences may only be resolved by political action. 


\section{References}

Anger A. (2014) Market-based policies for aviation - where next? Carbon Management 5: 211-213.

Anger A and Köhler J. (2010) Including aviation emissions in the EU ETS: Much ado about nothing? A review. Transport Policy 17: 38-46.

Australian Bureau of Statistics. (2017a) Australian Demographic Statistics, March 2017 Cat. no. 3101.o. Canberra: ABS.

Australian Bureau of Statistics. (2017b) Australian National Accounts: National Income, Expenditure and Product, Jun 2017. Cat. no. 5206.o. Canberra.

Australian Bureau of Statistics. (2017c) Average Weekly Earnings, Australia, May 2017. Cat. no. 6302.o. Canberra: ABS.

Australian Bureau of Statistics. (2017d) Consumer Price Index, Australia, Sept 2017 Cat. no. 6401.o. Canberra.

Australian Bureau of Statistics. (2017e) Labour Force, Australia, Detailed, Quarterly, Aug 2017. Cat. no. 6291.o. Canberra.

Australian Competition and Consumer Commission. (2015) Report to the Minister pursuant to s 6oJ of the Competition and Consumer Act 2010: Information about the ACCC's operations during the June 2015 quarter relating to the carbon tax price reduction obligation. Canberra: Australian Competition and Consumer Commission.

Australian Government. (2013) Review of the Clean Energy Future Household Assistance Package. The Treasury and the Department of Families, Housing, Community Services and Indigenous Affairs.

Baker D, Merkert R and Kamruzzaman M. (2015) Regional aviation and economic growth: Cointegration and causality analysis in Australia. Journal of Transport Geography 43: 140-150.

Becken S and Mackey B. (2017) What role for offsetting aviation greenhouse gases in a deepcut carbon world? Journal of Air Transport Management 63: 71-83.

BITRE. (2017a) Australian Domestic Airline Activity-time series. Available at: https://bitre.gov.au/publications/ongoing/domestic airline activitytime series.aspx.

BITRE. (2017b) Domestic Air Fare Indexes. Available at: https://bitre.gov.au/statistics/aviation/air fares.aspx.

BITRE. (2017c) Monthly Airline Performance. Available at: https://bitre.gov.au/publications/ongoing/domestic airline activitytime series.aspx.

Blonigen B and Cristea A. (2012) Airports and Urban Growth: Evidence from a Quasi-natural Policy Experiment. Working Paper No. 18278. Cambridge, MA: National Bureau of Economic Research.

Boeing. (2017) Current Market Outlook 2017-2036. Available at: https://www.boeing.com/commercial/market/current-market-outlook-2017/.

Bows A, Anderson K and Peeters P. (2009) Air transport, climate change and tourism. Tourism and Hospitality Planning \& Development 6: 7-20.

Bows A, Anderson K and Upham P. (2006) Contraction \& Convergence: UK carbon emissions and the implications for UK air traffic. Manchester: Tyndall Centre for Climate Change Research.

Bray M and Wailes N. (1999) Reinterpreting the 1989 Pilots' Dispute: The role of managerial control and labour productivity. Labour \& Industry 10: 79-105. 
Carbon Market Watch. (2016) The CORSIA: ICAO's Market Based Measure and Implications for Europe - Carbon Market Watch Policy Briefing. Available at: https://carbonmarketwatch.org/wp-content/uploads/2016/10/Post-AssemblyPolicy-Brief-Web.pdf.

Clean Energy Regulator. (2012) Guide to Carbon Price Liability under the Clean Energy Act 2011. Canberra: Commonwealth of Australia.

Cui Q and Li Y. (2017a) Airline efficiency measures under CNG2O2O strategy: An application of a Dynamic By-production model. Transportation Research Part A: Policy and Practice 106: 130-143.

Cui Q and Li Y. (2017b) Will airline efficiency be affected by "Carbon Neutral Growth from 2020" strategy? Evidences from 29 international airlines. Journal of Cleaner Production 164: 1289-1300.

Cui Q, Li Y and Wei Y-M. (2017) Exploring the impacts of EU ETS on the pollution abatement costs of European airlines: An application of Network Environmental Production Function. Transport Policy 60: 131-142.

Cui Q, Wei Y-M and Li Y. (2016a) Exploring the impacts of the EU ETS emission limits on airline performance via the Dynamic Environmental DEA approach. Applied Energy 183: 984-994.

Cui Q, Wei Y-M, Yu C-l, et al. (2016b) Measuring the energy efficiency for airlines under the pressure of being included into the EU ETS. Journal of Advanced Transportation 50: $1630-1649$.

De Roos N, Mills G and Whelan K. (2010) Pricing dynamics in the Australian airline market. Economic Record 86: 545-562.

Department of the Environment and Energy. (2017) Australian Petroleum Statistics Issue 246, January 2017. Canberra: Australian Government.

Douglas EJ. (1993) Airline competition and strategy in Australia. School of Business Discussion Papers. Gold Coast: Bond University.

Dwyer L, Forsyth P, Spurr R, et al. (2013) Economic impacts of a carbon tax on the Australian tourism industry. Journal of Travel Research 52: 143-155.

Faulkner B. (2003) Evaluating the tourism impacts of hallmark events. In: Fredline L, Jago L and Cooper C (eds) Progressing Tourism Research Bristol: Multilingual Matters, 93113 .

Fuellhart K, Derudder B, O'Connor K, et al. (2015) Geographic correlates of lowest available airfares on Australian air routes. Journal of Air Transport Studies 6: 1-22.

Fuellhart K and O'Connor K. (2013) Air services at Australian cities: Change and inertia 2005-2010. Geographical Research 51: 37-48.

Green R. (2007) Airports and economic development. Real Estate Economics 35: 91- 112.

Gudmundsson SV and Anger A. (2012) Global carbon dioxide emissions scenarios for aviation derived from IPCC storylines: A meta-analysis. Transportation Research Part D: Transport and Environment 17: 61-65.

Higham J, Ellis L and Maclaurin J. (2018) Tourist aviation emissions: A problem of collective action. Journal of Travel Research.

IATA. (2013) Resolution on the Implementation of the Aviation "CNG2O2O" Strategy. Available at: https://www.iata.org/pressroom/pr/Documents/agm69-resolutioncng2020.pdf.

IATA. (2017) Annual Review 2017. Available at:

http://www.iata.org/publications/Documents/iata-annual-review-2017.pdf. 
ICAO. (2017a) Carbon Offsetting and Reduction Scheme for International Aviation Implementation Plan. Available at: https://www.icao.int/environmentalprotection/Documents/CorsiaBrochure 8Panels-ENG-Web.pdf.

ICAO. (2017b) International Civil Aviation Organization's Carbon Offset and Reduction Scheme for International Aviation (CORSIA).

ICAO. (2017c) What would be the impact of a global MBM scheme for international aviation? Available at: https://www.icao.int/Meetings/HLMMBM/Pages/FAQ3.aspx.

ICAO. (2017d) The World of Air Transport in 2016. Available at: https://www.icao.int/annual-report-2016/Pages/the-world-of-air-transport-in2016.aspx.

International Monetary Fund. (2017) NYMEX Futures Prices. Washington D.C.

Janda M. (2014) Virgin Australia dips to $\$ 84$ million loss despite revenue rise. Australian Broadcasting Corporation News.

Jotzo F. (2012) Australia's carbon price. Nature Climate Change 2: 475-476.

Lee DS, Fahey DW, Forster PM, et al. (2009) Aviation and global climate change in the 21st century. Atmospheric Environment 43: 3520-3537.

Leiper N. (2002) Why Ansett Airlines Failed and How to Prevent It Happening Again. Current Issues in Tourism 5: 134-148.

Li Y and Cui Q. (2017) Carbon neutral growth from 2020 strategy and airline environmental inefficiency: A network range adjusted environmental data envelopment analysis. Applied Energy 199: 13-24.

Lim C. (2006) A survey of tourism demand modelling practice: Issues and implications. In: Dwyer L and Forsyth P (eds) International handbook on the economics of tourism. Cheltenham, UK; Northampton, USA: Edward Elgar, 45-72.

Macintosh A and Wallace L. (2009) International aviation emissions to 2025: Can emissions be stabilised without restricting demand? Energy Policy 37: 264-273.

Marazzo M, Scherre R and Fernandes E. (2010) Air transport demand and economic growth in Brazil: A time series analysis. Transportation Research Part E: Logistics and Transportation Review 46: 261-269.

Mayor K and Tol RSJ. (2007) The impact of the UK aviation tax on carbon dioxide emissions and visitor numbers. Transport Policy 14: 507-513.

O'Gorman M and Jotzo F. (2014) Impact of the Carbon Price on Australia's Electricity Demand, Supply and Emissions CCEP Working Paper No. 1411. Crawford School of Public Policy, The Australian National University.

Peeters P, Higham J, Kutzner D, et al. (2016) Are technology myths stalling aviation climate policy? Transportation Research Part D 44: 30-42.

PwC. (2017) The Economic Impact of Air Taxes in Europe. London: PricewaterhouseCoopers.

Qantas. (2013) QANTAS Annual Report 2013. Available at: http://investor.qantas.com/FormBuilder/ Resource/ module/doLLG5ufYkCyEPjF1 tpgyw/file/annual-reports/2013AnnualReport.pdf.

Qantas. (2014) Annual Report 2014. Available at: http://investor.qantas.com/FormBuilder/ Resource/ module/doLLG5ufYkCyEPjF1 tpgyw/file/annual-reports/2014AnnualReport.pdf.

Qantas Airways Limited. (2013) The Transformation Continues: QANTAS Annual Report 2013.

Reserve Bank of Australia. (2017) Exchange Rates - Monthly. 
Scheelhaase J, Maertens S, Grimme W, et al. (2018) EU ETS versus CORSIA - A critical assessment of two approaches to limit air transport's $\mathrm{CO} 2$ emissions by market-based measures. Journal of Air Transport Management 67: 55-62.

Scott D, Hall CM and Gössling S. (2016) A report on the Paris Climate Change Agreement and its implications for tourism: Why we will always have Paris. Journal of Sustainable Tourism 24: 933-948.

Sellner R and Nagl P. (2010) Air accessibility and growth - the economic effects of a capacity expansion at Vienna International Airport. Journal of Air Transport Management 16.

Stern N. (2006) The Stern Review: The Economics of Climate Change, Cambridge: Cambridge University Press.

Surgenor C. (2014) As Australia repeals carbon tax, Qantas removes its domestic flight surcharge but says fares won't drop. Available at: http://www.greenaironline.com/news.php?viewStory=1947.

Virgin Australia. (2013) Annual Report 2013. Available at: https://www.virginaustralia.com/cs/groups/internetcontent/@wc/documents/webc ontent/ edisp/annual-rpt-2013.pdf.

Virgin Australia. (2014) Annual Financial Report 2014. Available at: https://www.virginaustralia.com/cs/groups/internetcontent/@wc/documents/webc ontent/ edisp/annual-financial-report-2014.pdf.

Wang M and Song H. (2010) Air Travel Demand Studies: A Review. Journal of China Tourism Research 6: 29-49.

World Bank. (2014) State and trends of carbon pricing 2014. Washington DC, 1-140.

World Bank. (2017) Air transport, passengers carried. Available at: http://data.worldbank.org/indicator/IS.AIR.PSGR. 